\title{
Perceptions of harm from electronic-cigarette use among a sample of US Navy personnel
}

\author{
Matthew T. Hall', Ryan Austin', Tai A. Do ${ }^{2}$, Alec G. Richardson ${ }^{3}$
}

\begin{abstract}
INTRODUCTION Scant information exists on the perceptions and behaviors surrounding electronic cigarette (EC) use in the U.S. military. The Health Belief Model (HBM) enables factors influencing behavior adoption to be assessed. Utilizing this model, this study explored five EC-related perceptions among a sample of active-duty Navy personnel.

METHODS Participants were invited to complete a questionnaire involving EC use and perceptions. Demographics were reported and perceptions assessed using multiple choice and answer questions. Analyses included benefit and harm ratios and non-parametric tests.

RESULTS Among the 977 participants, 29.7\% tried ECs, 9.5\% were current users and 3.8\% were dual users. A large proportion of the population believed that ECs were less harmful than cigarettes, the safest alternative to cigarettes, accepted by non-users, and allowed in areas where cigarettes are prohibited. On the other hand, the majority believed that ECs did not make the user look cool or fit in and were not safe to use around children. EC users, cigarette smokers, men, those under 30 years of age, and those with less than a bachelor degree were more likely to have positive beliefs and perceptions about EC use.

Conclusions The majority of the population studied has negative perceptions and beliefs about EC use. Several groups have beliefs that highlight vulnerabilities to EC experimentation and use. The findings illustrated concepts related to cessation and behavior adoption, harm-to-self and second-hand vapor, and smoke-free zones. These findings may help to identify motivations for experimentation and use, as well as to direct future EC intervention and prevention efforts.
\end{abstract}

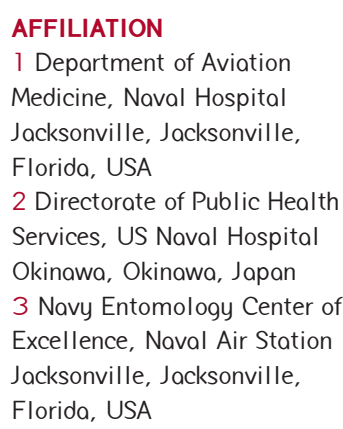

AFFILIATION

1 Department of Aviation Medicine, Naval Hospital Jacksonville, Jacksonville, Florida, USA

2 Directorate of Public Health

Services, US Naval Hospital

Okinawa, Okinawa, Japan

3 Navy Entomology Center of

Excellence, Naval Air Station

Jacksonville, Jacksonville,

Florida, USA

\section{CORRESPONDENCE TO}

Matthew T. Hall. UNC School of Medicine, 590 Manning Drive

Chapel Hill, NC 27599, United

States.

E-Mail: matthew.hall2@

unchealth.unc.edu

\section{KEYWORDS}

smoking cessation, beliefs, perception, electronic-cigarettes, behavior adoption

Received: 4 April 2017

Revised: 4 October 2017

Accepted: 9 October 2017

\section{INTRODUCTION}

Electronic cigarette (EC) use is an emerging health trend with unknown health consequences. Individuals may experiment with ECs for a variety of reasons, the most common being smoking cessation and novelty ${ }^{1,2}$. Scant information is available regarding perceptions of EC harms in the U.S. military population, a group with unique characteristics that render them, paradoxically, both protected and vulnerable to harmful health behaviors. This study describes EC harm beliefs and perceptions using a sample of active-duty U.S. Navy personnel. The harm beliefs studied in this investigation focus on a behavior motivational structure in an effort to uncover vulnerabilities and identify avenues for prevention, intervention and cessation.

Exploring the perceptions of EC harm can provide insight into adoption and cessation behaviors. The health belief model (HBM) is a useful tool for exploring the motivations and factors behind health behavior decisions. This model utilizes the concepts of perceived susceptibility, severity, benefits, barriers, cues to action, and self-efficacy to explain behaviors and target interventions ${ }^{3}$. Additionally, the HBM has been 
shown to be beneficial in assessing perceived harms and cessation intentions in relation to EC use ${ }^{4}$.

The prevalence of tobacco use within the U.S. military is markedly higher than its civilian counterpart ${ }^{5,6}$. The U.S. Navy closely mirrors the overall U.S. military in smoking frequency prevalence $(8.3 \%, 8.2 \%$ infrequent smokers; $12.6 \%$, $12.6 \%$ light/moderate smokers; $3.4 \%, 3.2 \%$ heavy smokers; respectively) ${ }^{6}$. Smoking is not only linked and causal to numerous diseases in the general population but it is also correlated with decreased operational performance in many U.S. military roles ${ }^{6,7}$. The potential for smokers to replace cigarettes with ECs, due in part to positive EC beliefs, presents concerns for the implications of EC use on military operational ability.

Tobacco products are often marketed as 'cool', 'accepted' and 'healthy' in an effort to influence individuals to try cigarettes. The appeal of tobacco products, as well as ECs, as 'cool' or 'uncool' relates to identity beliefs and can strongly influence behavior. Being 'cool' is a socially desirable characteristic that contributes to behavior adoption and experimentation ${ }^{2,8}$. Similarly, the perception of ECs as uncool has been also one of the main reasons for EC cessation ${ }^{8}$. Although not explicitly described in the context of being cool or uncool, some avoid EC use because they believe that EC users are old and addicted to nicotine? .

Smokers may attempt cessation with ECs as a harmreduction strategy because of a common belief that ECs are healthier than cigarettes ${ }^{4,8-11}$. The general population's beliefs fluctuate widely regarding the health effects of ECs compared to cigarettes. Studies have revealed that most believe that ECs are less harmful than cigarettes and even some believe that they are harmless ${ }^{11-14}$. Even when EC users have concerns about safety, there is a pervasive belief that ECs are a healthier alternative to cigarettes and that the harmful effects of cigarettes outweigh the consequences of EC use ${ }^{12,15}$. A study of health-care professionals and cessation counselors found that 83\% believed ECs were healthier than cigarettes but still did not recommend them as a cessation technique; however recent evidence suggests that this positive belief is waning ${ }^{16,17}$.

Beliefs regarding EC use around children can be used as a comparative criterion for assessing the perceived harm of ECs. Selling cigarettes to minors is illegal nationally and it is widely prohibited for children to smoke; many U.S States are following with similar EC use restrictions ${ }^{18}$. Anecdotally, most individuals believe that cigarettes are not safe to be used around children. In contrast, 16 to $30 \%$ of current EC users may believe ECs are safe to use around family, friends, and children ${ }^{13}$. This is a concern, because if one compares EC risk to tobacco risk, the perceived risk of second-hand smoke and the perceived risk to children are highly correlated ${ }^{19}$. The beliefs regarding second-hand exposure risk seem to vary by population with EC users more often affirming the safety of EC vapor, while the general population more often tended to believe that the vapor was harmful ${ }^{11,12,20}$.

The advent of ECs as an alternative to smoking, while not being subjected to the same regulations as cigarettes, presents a unique context for this emerging behavior. Smokefree zones are becoming more prevalent, and cigarette users are becoming less welcome in public places ${ }^{18}$. Some antitobacco groups favor EC use in smoke-free areas due to the perceived low second-hand risk ${ }^{21}$. Evidence indicates that healthcare providers are divided on EC-use-area prohibition with wide ranges of $16 \%$ to $62 \%$ favoring use in cigaretteprohibited areas ${ }^{16,22}$. The belief that ECs can be used indoors or where cigarettes are prohibited, such as in schools or at work, is appealing to smokers ${ }^{8,11,13,15}$. One study found that EC experimentation was 4 times higher in groups that believed ECs could be used anywhere ${ }^{8}$. Increased restrictions on cigarette use, especially in the context of unclear and variable EC regulations, may provide a motivation for individuals to try ECs and become regular EC users ${ }^{15,18}$.

The role of perceptions and beliefs in behavior adoption is critical to understanding modes of intervention and cessation. A wealth of perception data exists regarding cigarette use, but comparatively little is available regarding EC use in the U.S military. Utilizing structured questions related to the HBM, this study: explores factors contributing to EC adoption and use, attempts to identify high-risk groups for EC use, and helps to focus efforts on prevention and cessation.

\section{METHODS}

This cross-sectional survey was conducted at the Naval Branch Health Clinic Jacksonville, Department of Aviation Medicine, in Jacksonville, Florida, during an 11-month period from August 2015 to June 2016. The participants in this study comprised active-duty U.S. Navy personnel who worked in either an aviation job (aircrew) or a non-aviation job (nonaircrew). Individuals who reported to the clinic for their required annual health-assessment were invited to participate in this study. On average, 200 annual health-assessments are conducted each month at the clinic.

The survey, entitled 'Assessment of Electronic Cigarette Use in the Aviation Community', was attached to the participant's health-assessment paperwork. The written informed consent preceded the survey and included a statement of purpose, description of risks, instructions, and contact information of the 
researchers. Participants were asked to report non-personally identifiable demographic information, smoking and EC use behaviors, and beliefs about EC use. Questions were modeled on the Center for Disease Control's Youth Risk Behavior Survey ${ }^{23}$. Participants were asked the following perception related questions:

'Do you believe any of the following are less harmful than smoking cigarettes?'

'Do you think electronic cigarettes are more accepted by nonsmokers?

'Do you think electronic cigarettes are allowed in areas where tobacco cigarettes are not allowed (such as in restaurants and movie theaters)?'

'Do you think electronic cigarettes make you or others look cool or fit in?'

'Do you think that electronic cigarettes are safe to be used around children?'

The answers were all multiple choice, utilizing multiple and single answer options, and a modified 5-point Likert-scale rating system. All submitted surveys were included in the analysis. Surveys that were missing, not filled in, or annotated that the participant declined to participate, were excluded from analysis. This study was approved by the Naval Hospital Portsmouth Institutional Review Board.

Demographic categories assessed included; age, sex, military rank, years of military service, highest level of education obtained, and current job (subcategories of aircrew and nonaircrew jobs). Military rank was used as a surrogate indicator of income level. Participants who reported any EC or cigarette use within the past 30 days were considered current users. Individuals who reported EC or cigarette use in the past but not within the past 30 days were considered former users, and those who reported never trying ECs or cigarettes were considered non-users.

\section{Statistical analysis}

The statistical analysis was conducted using Intel Visual Fortran Compiler XE 2013 and Microsoft Excel 2016. Descriptive statistics (i.e. frequencies, prevalence rates, etc.) were computed. Hypothesis testing was conducted using a preliminary goodness-of-fit (GOF) analysis to determine whether the datasets conform to normal and homoscedastic behavior; these included the Kolmogorov-Smirnov and Bartlett test ${ }^{24-26}$. The GOF analysis showed that the datasets conformed to non-normal and heteroscedastic behavior; hence the non-parametric Kruskal-Wallis test was appropriate ${ }^{27}$. An optimal post-hoc multiple-comparison test was conducted for each of the factors and interactions, to identify the specific pairwise combinations of levels of each factor and interaction contributing to overall variability ${ }^{28}$. Post-hoc tests used in this analysis included the Tukey multiple-comparison test, Newman-Keuls and Duncan multiple-range tests, and Scheffe multiple-contrast test (as identified from a post-hoc optimization analysis $)^{29-35}$.

Benefit ratios, defined as the proportion of individuals that perceived ECs as beneficial, were calculated for 5 different types of perceptions, as the ratio of counts of individuals that perceived ECs as beneficial to the total counts of individuals. Ratios ranged from 0 (not beneficial) to 1 (completely beneficial) (Fig. 1). Detriment ratios were conducted in the same way as the benefit ratio but for perceived harm. Regression analyses were conducted to assess correlations of the 5 different Benefit Ratios versus the EC-use frequency and demographic groups. A power analysis was conducted for each test to determine if the sample size was statistically adequate, and to identify precision and confidence intervals ${ }^{28}$. Missing values were excluded from individual calculations. The level of significance was set at 0.05 with a corresponding confidence interval of $95 \%$.

Demographic factors were grouped into larger categories in order to obtain statistical significance, as indicated by a posthoc power analysis. The 25 military-rank options were divided into five groups: junior enlisted (E1-E5), senior enlisted (E6-E9), warrant officer (CWO1-CWO5), junior officer (Midshipman-03), and senior officer (O4-O10). Education levels were reorganized into those with less than a bachelor degree and a bachelor degree or higher. Jobs were binned from 6 categories (administration or other support, aircrew, maintenance, naval flight officer, pilot, and other) into aircrew and non-aircrew. This study will refer to all individuals whose job involves flying, as 'aircrew', and all individuals whose job does not involve flying, as 'non-aircrew'.

\section{RESULTS}

There were 977 individuals included in this study (Table 1) with an approximate response rate of $40.7 \%$. Among the study respondents, $84 \%$ identified as male, $62 \%$ were less than 30 years of age, and $62.1 \%$ had less than a 4 -year degree. The results were comparable to the local Naval Station Jacksonville active-duty population; $79.46 \%$ male and $57.23 \%$ less than 30 years of age $\mathrm{e}^{36}$. In regard to military specific demographic factors, $71 \%$ had 10 or fewer years of time-in-service (TIS), $68 \%$ were enlisted, and $58.8 \%$ were aircrew. Nearly a third (29.7\%) of the study population tried ECs and 9.3\% were current users. More than half of the participants tried cigarettes (54\%) and $14.9 \%$ were current users. Only $3.8 \%$ of the study 
Fig 1. Mean benefit ratios foreach of the 5types of perceptions. The expressed value is the ratio of findividuals that perceived the electronic cigarettes as beneficial to the total counts of individuals. Ratios range firom 0 (no benefit) to 1 (completely beneficial).

\begin{tabular}{|c|c|c|c|c|c|c|c|c|c|c|c|c|}
\hline & & \multirow{2}{*}{$\begin{array}{l}\text { Benefit } \\
\text { Total opulation } \\
977\end{array}$} & \multicolumn{2}{|c|}{$\begin{array}{l}\text { ECsare less harmful than } \\
\text { cigarettes }\end{array}$} & \multicolumn{2}{|c|}{ ECsare more accepted by non smokers } & \multicolumn{2}{|c|}{$\begin{array}{l}\text { ECs are allowed in areas where } \\
\text { cigarettes are rohibited }\end{array}$} & \multicolumn{2}{|c|}{ ECs make the user or others look cool or fit in } & \multicolumn{2}{|c|}{ ECsare safe to be used around children } \\
\hline & & & Benefit ratio (SD) & $\begin{array}{l}\% n \\
10.6(104)\end{array}$ & Benefit ratio (SD) & $\begin{array}{l}\% n \\
41.0(401)\end{array}$ & Benefit ratio (SD) & $\begin{array}{l}\% \mathrm{n} \\
21.9(214)\end{array}$ & Benefit ratio (SD) & $\begin{array}{l}\% \mathrm{n} \\
1.5(15)\end{array}$ & Benefit ratio (SD) & $\begin{array}{l}\% \mathrm{n} \\
4.0(39)\end{array}$ \\
\hline \multirow[t]{3}{*}{ Gender } & Male & $84.0(821)$ & $0.1264(0.0715)$ & $12.9(94)$ & $0.6392(0.0984)$ & $46.4(339)$ & $0.4041(0.0947)$ & $24.8(182)$ & $0.2135(0.0465)$ & $1.5(11)$ & $0.1916(0.0542)$ & $4.9(36)$ \\
\hline & Female & $15.5(151)$ & $0.0605(0.0561)$ & $6.6(9)$ & $0.6350(0.1933)$ & $43.7(59)$ & 0.3500 & $22.4(30)$ & $0.1336(0.1097)$ & $3.0(4)$ & $0.1142(0.1318)$ & $2.2(3)$ \\
\hline & & & & & & & $(0.1488)$ & & & & & \\
\hline \multirow[t]{3}{*}{ Age } & under 30 years & $62.0606)$ & $0.1253(0.0866)^{* * * *}$ & $13.4(73)$ & $0.6826(0.0893)$ & $49.5(268)$ & $0.4300(0.1071)$ & $27.3(148)$ & $0.2290(0.0783)$ & $2.0(11)$ & $0.1904(0.0681)^{* * *}$ & $5.4(29)$ \\
\hline & 30-45 years & $36.7(359)$ & $0.1059(0.0795)$ & $9.7(31)$ & $0.5814(0.0863)$ & $41.5(132)$ & $0.3548(0.0866)$ & $20.7(66)$ & $0.1640(0.0737)$ & $1.3(4)$ & $0.1820(0.0886)$ & $3.1(10)$ \\
\hline & over 45 years & $1.2(12)$ & $0.0000(0.0000)$ & $0.0(0)$ & $0.4762(0.5040)$ & $10.0(1)$ & $0.2857(0.1844)$ & $\mathrm{o}(0)$ & $0.2143(0.3934)$ & $0(0)$ & $0.1429(0.3780)$ & $0(0)$ \\
\hline \multirow[t]{2}{*}{ Education } & $\begin{array}{l}\text { Less than bachelor } \\
\text { degree }\end{array}$ & 62.1 (607) & $0.1261(0.0630)$ & $13.6(73)$ & $0.6682(0.1035)$ & $49.3(263)$ & $0.4149(0.1016)$ & $24.2(130)$ & $0.2337(0.0660)^{*}$ & $1.9(10)$ & $0.2259(0.0558)^{* * *}$ & $6.0(32)$ \\
\hline & $\begin{array}{l}\text { Bachelor degree or } \\
\text { higher }\end{array}$ & $37.4(365)$ & $0.1042(0.0818)$ & $9.4(31)$ & $0.6182(0.1296)$ & $41.4(137)$ & $0.3748(0.1057)$ & $24.8(82)$ & $0.1650(0.0868)$ & $1.5(5)$ & $0.1134(0.0586)$ & $2.1(7)$ \\
\hline \multirow[t]{5}{*}{ Paygrade } & Junior enlisted & $48.1(470)$ & $0.1205(0.0580)$ & $13.2(55)$ & $0.6779(0.1073)$ & $48.3(201)$ & $0.4233(0.1183)$ & $25.4(106)$ & $0.2513(0.0705)^{* * * *}$ & $2.4(10)$ & $0.1980(0.0609)$ & $5.8(24)$ \\
\hline & Senior enlisted & $19.9(194)$ & $0.1348(0.1061)$ & $13.3(22)$ & $0.6409(0.1512)$ & $43.7(73)$ & $0.3693(0.1323)$ & $17.8(30)$ & $0.1942(0.0939)$ & $0.6(1)$ & $0.2712(0.1445)^{*}$ & $4.8(8)$ \\
\hline & Warrant officer & $4(0.4)$ & $0.1667(0.2887)$ & $33.3(1)$ & $0.3333(0.5774)$ & $0(0)$ & $0.3333(0.5774)$ & $33.3(1)$ & $0.0000(0.0000)$ & $0(0)$ & $0.0000(0.0000)$ & $\mathrm{O}(0)$ \\
\hline & Junior officer & 23.7 (232) & $0.0938(0.0951)$ & $10.3(22)$ & $0.6507(0.1446)$ & $47.2(101)$ & $0.4240(0.0999)$ & $29.0(62)$ & $0.1842(0.1064)$ & $1.9(4)$ & $0.1138(0.0993)$ & 1.9 (4) \\
\hline & Senior officer & $7.8(76)$ & $0.1535(0.3155)$ & $5.8(4)$ & $0.5296(0.1889)$ & $38.2(26)$ & $0.2668(0.2234)$ & $22.1(15)$ & $0.0548(0.0887)$ & $0(0)$ & $0.1701(0.3120)$ & $4.4(3)$ \\
\hline \multirow{8}{*}{$\begin{array}{l}\text { Time-in- } \\
\text { service }\end{array}$} & $1-2$ years & $21.4(209)$ & $0.1049(0.1067)$ & $11.0(21)$ & $0.6630(0.1590)$ & $40.5(77)$ & $0.4135(0.1497)$ & $45(23.8)$ & $0.2487(0.1250)^{*}$ & $7(3.7)$ & $0.1481(0.1039)$ & $8(4.2)$ \\
\hline & $3-6$ years & $33.4(326)$ & $0.1419(0.0651)^{*}$ & $15.3(45)$ & $0.7051(0.0988)$ & $54.4(160)$ & $0.4445(0.1122)$ & $89(30.1)$ & $0.2191(0.0843)$ & $4(1.4)$ & $0.2039(0.0721)^{*}$ & $18(6.1)$ \\
\hline & $7-10$ years & $16.2(158)$ & $0.1210(0.1009)$ & $13.9(19)$ & $0.6105(0.1654)$ & $47.8(65)$ & $0.3650(0.1032)$ & $28(20.6)$ & $0.2124(0.0907)$ & $2(1.5)$ & $0.1498(0.0992)$ & $3(2.2)$ \\
\hline & 11-14 years & $12.0(117)$ & $0.1278(0.1596)$ & $9.5(10)$ & $0.6705(0.1840)$ & $44.8(47)$ & $0.3495(0.2167)$ & $24(22.6)$ & $0.1851(0.1023)$ & $2(1.9)$ & $0.2248(0.1578)$ & $7(6.6)$ \\
\hline & $15-18$ years & $9.3(91)$ & $0.0606(0.0844)$ & $6.3(5)$ & $0.5526(0.1958)$ & 40.5 (32) & $0.3576(0.1831)$ & $13(16.3)$ & $0.1379(0.1462)$ & $O(0)$ & $0.2281(0.1589)$ & $2(2.5)$ \\
\hline & 19-22 years & $5.3(52)$ & $0.0487(0.1086)$ & $7.0(3)$ & $0.4583(0.3030)$ & $26.2(11)$ & $0.4109(0.2738)$ & $9(21.4)$ & $0.2053(0.1921)$ & $0(0)$ & $0.2047(0.2327)$ & $1(2.4)$ \\
\hline & 23-25 years & $1.3(13)$ & $0.1667(0.4082)$ & $8.3(1)$ & $0.5000(0.4595)$ & $46.2(6)$ & $0.5000(0.4595)$ & $6(46.2)$ & $0.0556(0.1361)$ & $0(0)$ & $0.0000(0.0000)$ & $O(0)$ \\
\hline & Over 25 years & $0.8(8)$ & $0.0000(0.0000)$ & $O(0)$ & $0.3889(0.4907)$ & $14.3(1)$ & $0.1667(0.4082)$ & $O(0)$ & $0.0000(0.0000)$ & $0(0)$ & $0.0000(0.0000)$ & $O(0)$ \\
\hline \multirow[t]{2}{*}{ Job } & Aircrew & $58.8(574)$ & $0.0985(0.0590)$ & $9.4(49)$ & $0.6418(0.1336)$ & $46.3(240)$ & $0.4020(0.0859)$ & 25.9 (135) & $0.1965(0.0864)$ & $1.9(10)$ & $0.1556(0.0599)$ & $3.9(20)$ \\
\hline & Non-aircrew & $40.8(399)$ & $0.1403(0.0791)$ & $15.8(55)$ & $0.6537(0.1108)$ & $45.4(158)$ & $0.3964(0.1451)$ & $22.3(78)$ & $0.2237(0.0761)$ & $1.2(4)$ & $\cdot 0.2277(0.0755)^{*}$ & $5.4(19)$ \\
\hline \multirow{3}{*}{$\begin{array}{l}\text { Smoking } \\
\text { Status }\end{array}$} & Current smoker & $14.9(146)$ & $0.1595(0.1409)$ & $20.6(26)$ & $0.17133(0.1907)$ & $62.2(79)$ & $0.4367(0.1527)$ & $33.1(42)$ & $0.2694(0.1050)^{*}$ & $0.8(1)$ & $0.2748(0.1556)^{*}$ & $8.7(11)$ \\
\hline & Former smoker & 39.1 (382) & $0.1588(0.1075)$ & $14.7(50)$ & $0.6581(0.1226)$ & $53.1(178)$ & $0.3931(0.1346)$ & $24.8(84)$ & $0.1654(0.0706)$ & $2.7(9)$ & $0.1735(0.0727)$ & $5.3(18)$ \\
\hline & Non-smoker & $45.2(442)$ & $0.0661(0.0318)$ & $6.7(27)$ & $0.6076(0.0886)$ & $35.3(143)$ & $0.3991(0.1113)$ & $21.8(88)$ & $0.2103(0.0573)$ & $1.2(5)$ & $0.1692(0.0598)$ & $2.5(10)$ \\
\hline \multirow[t]{3}{*}{ EC status } & Current EC user & $9.3(91)$ & $0.4334(0.1818)^{* * *}$ & $48.8(39)$ & $0.7717(0.1605)^{*}$ & $77.2(61)$ & $0.4729(0.1825)$ & $32.5(26)$ & $0.2630(0.1579)$ & $0(0)$ & $0.4518(0.1774)^{* * * *}$ & $21.3(17)$ \\
\hline & Former EC user & $20.4(199)$ & $0.1728(0.1474)$ & $19.1(34)$ & $0.7568(0.1320)$ & $67.0(120)$ & $0.4179(0.1532)$ & $32.4(58)$ & $0.2618(0.1074)$ & $3.9(7)$ & $0.2170(0.0905)$ & 7.9 (14) \\
\hline & Non-user & $68.8(672)$ & $0.0505(0.0279)$ & $4.8(29)$ & $0.5815(0.0715)$ & 35.9 (218) & $0.3793(0.1032)$ & $21.3(130)$ & $0.1804(0.0434)$ & $1.3(8)$ & $0.1391(0.0449)$ & $1.3(8)$ \\
\hline
\end{tabular}


population were considered dual users (currently use ECs and cigarettes).

Benefit 1: Perception that ECs are less harmful than cigarettes.

When given the option of comparing relative harm of cigarettes to other nicotine and tobacco sources, the majority $(63.4 \%)$ felt that cigarettes were the most harmful of all the options. ECs were the single greatest nicotine alternative considered to be safer than cigarettes (11.9\%), followed by chewing tobacco $(2.1 \%)$, snuff or dip (1.9\%), snus (1.0\%), and dissolvable nicotine products $(0.3 \%)$.

EC users perceived that ECs were less harmful than cigarettes, whereas non-EC users were the least likely to believe this ( $48.8 \%$ and $4.8 \%$, respectively, $\mathrm{p}<0.0001$ ). Those under 30 years of age were more likely to believe that ECs were safer than other tobacco products, whereas those over 45 were the least likely $(\mathrm{p}<0.0001)$. Participants with 3-6 years TIS were more likely to perceive ECs as less harmful than other tobacco products $(\mathrm{p}=0.0047)$. Important to note but not reaching a level of statistical significance, men and former cigarette smokers were more likely to perceive ECs as less harmful than other tobacco products.

Benefit 2: Perception that ECs are more accepted by nonsmokers.

Among the study population, $41.0 \%$ believed that ECs either definitely or probably were more accepted by nonsmokers. EC users, compared to non-users, perceived that EC use was more accepted by non-smokers $(77.2 \%$ and $35.9 \%$, respectively, $\mathrm{p}=0.0028$ ). Current cigarette smokers and men were more likely to perceive ECs as more accepted by nonsmokers, but the finding was not statistically significant.

Benefit 3: Perception that ECs are allowed in areas where cigarettes are prohibited.

Only $21.9 \%$ of the study population had a positive perception regarding whether ECs should be used in areas where cigarettes are prohibited. EC users, current cigarette smokers, and men, were more likely to believe ECs should be allowed in areas where smoking is prohibited, but these findings were not statistically significant. Increased frequency of EC use among men was correlated to a greater perception of ECs being allowed in smoking-prohibited areas $(\mathrm{p}=0.0208)$. The belief of area restriction was correlated with frequency of EC use and education; those with greater than a bachelor degree demonstrated a negative correlation $(\mathrm{p}=0.0227)$.

Benefit 4: Perception that ECs make the user or others look cool or fit in.

Most (98.5\%) believed that ECs either probably or definitely did not make the user look cool or fit in. Current cigarette smokers were more likely to believe that using ECs made them look cool or fit in ( $\mathrm{p}=0.0439)$. The perception that ECs made someone look cool or fit in was highest for junior enlisted, and lowest for warrant officers $(\mathrm{p}<0.0001)$. Similarly, individuals with the least amount of TIS, 1-2 years, had the highest positive perception $(\mathrm{p}=0.0046)$. The strength of the positive belief among non-aircrew was positively correlated with the frequency of EC use $(\mathrm{p}=0.0338)$. Men were more likely to have a positive cool perception, but this finding did not reach a level of statistical significance. Those with less than a bachelor degree were more likely to believe that ECs made someone look cool or fit in ( $\mathrm{p}=0.0408)$, with both high and low education levels demonstrating a positive correlation between the frequency of EC use and the positive perception $(\mathrm{p}=0.0148)$.

Benefit 5: Perception that ECs are safe to be used around children.

The majority of the study population (70.7\%) believed that ECs are either probably or definitely not safe to be used around children, and only $4 \%$ affirmed a positive perception. Current EC users, compared to non-users, were more likely to believe that ECs were safe to be used around children $(p<0.0001)$. Current smokers, followed by former smokers, were more likely to believe that ECs were safe to use around children ( $\mathrm{p}=0.0442)$. Those under 30 years of age and those with less than a college degree had a stronger belief that ECs were safe to be used around children ( $\mathrm{p}=0.0186$ and $\mathrm{p}=0.0008$, respectively). Men were more likely to believe that ECs were safe to be used around children, but this finding did not reach statistically significant levels.

Military demographics elucidated notable findings in that senior enlisted individuals, those with 3-6 years TIS, and those who worked in non-aircrew fields, had the strongest belief that ECs were safe to use around children $(p=0.0026, p=0.0010$ and $\mathrm{p}=0.0168$, respectively). Non-aircrew EC-use frequency was positively correlated with the belief of safety around children $(\mathrm{p}=0.0046)$.

\section{Correlations}

When controlling for junior and senior enlisted, the frequency of EC use was positively correlated with all perceived benefits, with the exception of being safer than cigarettes (junior enlisted showed a negative correlation). When controlling for aviation status, the frequency of EC use was positively correlated with the perception of ECs being safer than cigarettes and with the perception that they should be used in areas where cigarettes are prohibited. In regard to the perceptions about the benefits of ECs being viewed as cool $(\mathrm{p}=0.0338)$ and safe to use around children $(\mathrm{p}=0.0046)$, non-aircrew were positively 
correlated with the belief in and the frequency of EC use. When considering education levels, benefit perceptions were uniformly positively correlated with EC-use frequency, except in regard to the benefits of use in areas where cigarettes are prohibited, in which case only those with less than a college degree showed a positive correlation. Similarly, greater harm was perceived by those with a college degree or higher in regard to EC use being allowed in places where cigarettes are prohibited $(\mathrm{p}=0.0227)$.

When considering age, EC-use frequency was negatively correlated for all perceptions of harm. In contrast, still controlling for age, cigarette frequency was uniformly positively correlated with all of the perceptions of harm. Comparatively, the frequency of cigarette smoking was negatively correlated with all benefit perceptions between the groups of over and under 30 years of age.

\section{DISCUSSION}

Beliefs and perceptions relating to EC use provide insight into the experimentation and adoption of this health behavior. The HBM framework allows for the extrapolation of beliefs and perceptions into a context of motivations for behavior change. In accordance with the HBM, the six areas explored in this study focus on an individual's perceived susceptibility (e.g. the harm of ECs), severity (e.g. in comparison to cigarettes), and benefits and barriers to use (e.g. cool). Elaborating on the adoption model, the unique questions explored in this study can be divided into three overarching actionable subjects: cessation and behavior adoption, harm-to-self and secondhand vapor, and smoke-free zones.

Many factors contribute to cessation and behavior adoption. Social acceptance of a behavior is critical to adoption. This study demonstrated that nearly half of the participants believed ECs were more likely to be accepted by non-smokers, and that this belief was strongest among EC users and cigarette smokers. An extension of social acceptance is the perception that ECs make someone 'look cool' or 'fit in'. The majority of the study population expressed some negative belief relating to ECs making someone look cool or fit in. However, select groups such as current EC users and cigarette smokers expressed positive beliefs. Similar trends were noted in certain similar militaryspecific demographics. For example, younger individuals with less than 2 years TIS and junior enlisted were also the most likely to express positive beliefs. The positive social acceptance belief, by groups most at risk to experimenting with or to continue using ECs (smokers, EC users, lower education and young men), highlights this as a potential avenue for exploring cessation and adoption intervention strategies.
Beliefs of harm-to-self and others impact on behavior adoption with regard to susceptibility and consequence severity. Individuals may seek ECs in an effort to reduce harm. In this study, more than half of the individuals believed cigarettes were more harmful than ECs, and believed ECs were the safest alternative to smoking. Similar to the perception of coolness, those most likely to believe ECs were safer than cigarettes were current EC users, young persons, and those with minimal TIS. Scant information exists on the safety of ECs, especially in comparison to cigarettes, but nonetheless certain groups are affirming positive beliefs.

Assessing the belief of whether ECs are safe to use around children was intended to explore two simultaneous beliefs: an alternative assessment of the harms of ECs, and the harm severity or risk of second-hand vapor. Similar to previous findings, the majority of the study population (70.7\%) believed ECs were not safe to be used around children; and only a very small percentage reported them as safe (4.0\%). This suggests that there is a pervasive belief, if only indirectly, that ECs pose a second-hand risk.

Military demographics demonstrated inconsistencies involving EC safety around children. Specifically, those with minimal TIS (3-6 years) and senior enlisted were more likely to express the positive belief. A unique division emerged; aircrew members expressed a predominantly negative belief (ECs are not safe to use around children), whereas nonaircrew members were more likely to have a positive belief. The divisions of aircrew and non-aircrew are interesting in that the demographic groups are primarily equal in representation and education, but aircrew members have historically demonstrated good health consciousness and outcomes $^{37,38}$.

The findings illustrate that the majority of the study population believe ECs are harmful, not only to the user but also to others. Still more important is that certain groups believe that ECs present little to no harm to self or others. The beliefs of limited harm harken back to the severity and susceptibility of a behavior in the context of behavior adoption and may contribute to EC experimentation and continued use. Focusing efforts on dispelling misinformation regarding EC-use harm may help guide health behavior interventions.

Smoke-free zones have reduced the prevalence of cigarette smoking, but little is known regarding current beliefs about how this applies to EC use ${ }^{39}$. This study found that approximately a quarter of the study population had a positive belief that ECs were not subject to the same area restrictions as cigarettes, not markedly different from previous studies ${ }^{40}$. Education demonstrated a bimodal perception in which high 
education level was associated with a negative perception, and low education level was associated with a positive perception. Men, cigarette smokers, and current EC users were the most likely to have a positive belief, although these findings did not reach significant levels. These belief-findings suggest that smoke-free zones, if intended to also restrict ECs, should be redefined to include all devices that present a second-hand respiratory risk.

This study was limited by several factors. The relatively low response rate of $40.7 \%$ and the recruitment design provides an opportunity for selection bias. While anonymous, the findings were self-reported and conducted in a clinical environment where individuals may have felt pressure to modify their responses. The use of the 30-day criteria for identifying current users, while widely used, is imperfect and may incorrectly estimate current use $^{41}$. The sample study population did not markedly vary from the Naval Station population, but it was still isolated to only active-duty Navy personnel involved at single location, thus there are limitations in the generalization of the findings.

\section{CONCLUSIONS}

The findings in this study strongly indicate that certain populations have a disproportionately positive view of EC use and risks. Individuals who are young, with less than a college education, and male, are more likely to believe that ECs are not subject to the same area restrictions as cigarettes, that ECs are less harmful than cigarettes, that ECs present a low second-hand risk, and that EC use appears 'cool'. Current cigarette users demonstrate a similar trend as men of having a positive perception of EC use, which may encourage these individuals to try ECs as a mode of smoking cessation. EC users demonstrate similar positive perceptions as cigarette users, and because of this, they have very little incentive to quit. The findings in this study help to elucidate EC behavior perceptions and may help to focus efforts toward dispelling health-risk misinformation, revising regulations and improving cessation.

\section{REFERENCES}

1. Malas M, van der Tempel J, Schwartz R, Minichiello A, Lightfoot C, Noormohamed A, Andrews J, Zawertailo L, Ferrence R: Electronic Cigarettes for Smoking Cessation: A Systematic Review. Nicotine Tob Res $2016 ; 18(10)$.

doi: $10.1093 / \mathrm{ntr} / \mathrm{ntw} 119$

2. Hall MG, Pepper JK, Morgan JC, Brewer NT: Social Interactions as a Source of Information about E-Cigarettes: A Study of U.S. Adult Smokers. Int J Environ Res Public Health. 2016; 13:(8). doi: 10.3390/ijerph13080788
3. Edberg, M: Essentials of Health Behavior. Social and Behavioral Theory in Public Health. 2nd ed. Burlington, MA: Jones and Bartlett Publishers, 2013.

4. Xu Y, Guo Y, Liu K, Liu Z, Wang X: E-Cigarette Awareness, Use, and Harm Perception among Adults: A Meta-Analysis of Observational Studies. PLoS One. $2016 ;(11): 11$.

doi:10.1371/journal.pone.0165938.

5. Durazzo TC, Mattsson N, Weiner MW; Alzheimer's Disease Neuroimaging Initiative. Smoking and increased Alzheimer's disease risk: a review of potential mechanisms. Alzheimers Dement. 2014 Jun; 10(3 Suppl):S122-45.

doi: 10.1016/j.jalz.2014.04.009

6. US Department of Health and Human Services. The Health Consequences of Smoking - 50 Years of Progress: A Report of the Surgeon General. Atlanta, GA: U.S. Department of Health and Human Services, Centers for Disease Control and Prevention, National Center for Chronic Disease Prevention and Health Promotion, Office on Smoking and Health, 2014.

7. Bondurant S, Wedge R. Combating Tobacco Use in Military and Veteran Populations. Institute of Medicine of the National Academies; 2009.

8. Kong G, Morean ME, Cavallo DA, Camenga DR, Krishnan-Sarin S: Reasons for Electronic Cigarette Experimentation and Discontinuation Among Adolescents and Young Adults. Nicotine Tob Res. 2014; (17):7. doi: $10.1093 /$ ntr/ntu257

9. Wagoner KG, Cornacchione J, Wiseman KD, Teal R, Moracco KE, Sutfin EL: E-cigarettes, Hookah Pens and Vapes: Adolescent and Young Adult Perceptions of Electronic Nicotine Delivery Systems. Nicotine Tob Res. 2016; (18):10.

doi: $10.1093 / \mathrm{ntr} / \mathrm{ntw} 095$

10. Tomashefski A: The perceived effects of electronic cigarettes on health by adult users: A state of the science systematic literature review. J Am Assoc Nurse Pract. 2016; (28): 9. doi: 10.1002/2327-6924.12358

11. Rutten LJ, Blake KD, Agunwamba AA, Grana RA, Wilson PM, Ebbert JO, Okamoto J, Leischow SJ: Use of E-Cigarettes Among Current Smokers: Associations Among Reasons for Use, Quit Intentions, and Current Tobacco Use. Nicotine Tob Res. 2015; (17):10. doi: $10.1093 / \mathrm{ntr} / \mathrm{ntv} 003$.

12. Martínez-Sànchez JM, Fu M, Martín-Sànchez JC, Ballbè M, Saltó E, Fernàndez E: Perception of electronic cigarettes in the general population: does their usefulness outweigh their risks? BMJ Open. 2015; (5):11.

doi: 10.1136/bmjopen-2015-009218

13. Volesky KD, Maki A, Scherf C, Watson LM, Cassol E, Villeneuve PJ: Characteristics of e-cigarette users and their perceptions of the benefits, harms and risks of e-cigarette use: survey results from a convenience sample in Ottawa, Canada. Health Promot Chronic Dis Prev Can. 2016, (36):7. doi: 10.24095/hpcdp.36.7.02

14. Awan KH: Experimentation and correlates of electronic nicotine delivery system (electronic cigarettes) among university students - A cross sectional study. Saudi Dent J. 2016; (28):2. doi: 10.1016/j.sdentj.2015.12.002

15. Wadsworth E, Neale J, McNeill A, Hitchman SC: How and Why Do Smokers Start Using E-Cigarettes? Qualitative Study of Vapers in London, UK. Int J Environ Res Public Health .2016; (13):7. 
doi: 10.3390/ijerph13070661

16. Van Gucht D, Baeyens F: Health professionals in Flanders perceive the potential health risks of vaping as lower than those of smoking but do not recommend using e-cigarettes to their smoking patients. Harm Reduct J. 2016; (13):1. doi:10.1186/s12954-016-0111-4

17. Huerta TR, Walker DM, Mullen D, Johnson TJ, Ford EW: Trends in E-Cigarette Awareness and Perceived Harmfulness in the U.S. Am J Prev Med. 2017; (52):3. doi: 10.1016/j.amepre.2016.10.017

18. Marynak K, Holmes CB, King BA, Promoff G, Bunnell R, McAfee T; Centers for Disease Control and Prevention (CDC): State laws prohibiting sales to minors and indoor use of electronic nicotine delivery systems--United States, November 2014. MMWR Morb Mortal Wkly Rep. 2014; (63):49.

19. Rosen L, Kostjukovsky I: Parental risk perceptions of child exposure to tobacco smoke. BMC Public Health. 2015;(15):90. doi:10.1186/s12889-015-1434-x

20. Tan AS, Lee CJ, Bigman CA: Comparison of beliefs about e-cigarettes' harms and benefits among never users and ever users of e-cigarettes. Drug Alcohol Depend. 2016; (15). doi: 10.1016/j.drugalcdep.2015.11.003

21. Green SH, Bayer R, Fairchild AL: Evidence, Policy, and E-Cigarettes. N Engl J Med. 2016; (375):5. doi: 10.1056/NEJMc1606395

22. Pippard BJ, Shipley MD: Healthcare staff attitudes towards the use of electronic cigarettes ('e-cigarettes') compared with a local trust policy. Perspect Public Health. 2016. doi: 1757913916659311

23. 2015 YRBS Questionnaire. National Center for HIV/AIDS, STD, and TB prevention; 2016.

24. Smirnov NV: On the estimation of the discrepancy between empirical curves of distribution for two independent samples. Bull Math Univ Moscou. 1939; (2):2.

25. Bartlett MS: Some examples of statistical methods of research in agriculture and applied biology. J Royal Statist Soc. 1937; (4 Suppl 2). doi: 10.2307/2983644

26. Bartlett MS: Properties of sufficiency and statistical tests. Proc Royal Statist Soc Ser A 1937;(160):901. doi: 10.1098/rspa.1937.0109

27. Kruskal WH, Wallis WA: Use of ranks in one-criterion analysis of variance. J Amer Statist Assoc 1952; (47):260. doi: $10.2307 / 2280779$

28. Zar JH: Biostatistical Analysis. 4th ed. New Jersey: Prentice Hall, 1999.

29. Tukey JW: One degree of freedom for non-additivity. Biometrics. 1949; 5:(3). doi: $10.2307 / 3001938$

30. Tukey JW: The problem of multiple comparisons. Department of Statistics, Princeton University. Unpublished [1953].

31. Newman D: The distribution of range in samples from a normal population, expressed in terms of an independent estimate of standard deviation. Biometrika. 1939; (31):1-2. doi: 10.2307/2334973

32. Duncan DB: A significance test for difference between ranked treatments in an analysis of variance. Virginia J Sci .1951; (2):3.

33. Duncan DB: Multiple range and multiple F tests. Biometrics. 1955; (11):1. doi: $10.2307 / 3001478$

34. Scheffe H: A method of judging all contrasts in the analysis of variance. Biometrika. 1953; (40):1-2.

doi: $10.2307 / 2333100$

35. Scheffe H: The Analysis of Variance. New York: Wiley, 1959.

36. Defense Medical Surveillance System (DMSS). Health.mil. Available at: http://www.health.mil/Military-Health-Topics/Health-Readiness/ Armed-Forces-Health-Surveillance-Branch/Data-Management-andTechnical-Support/Defense-Medical-Surveillance-System. Updated Oct 2014. (accessed January 2017).

37. York E, Mitchell RE, Graybiel A: Cardiovascular epidemiology, exercise, and health: 40-year followup of the U.S. Navy's «1000 aviators». Aviat Space Environ Med .1986; (57):6.

38. MacIntyre NR, Mitchell RE, Oberman A, et al. Longevity in military pilots: 37-year followup of the Navy's «1000 aviators». Aviat Space Environ Med.1978; (49):9.

39. Azagba S: Effect of smoke-free patio policy of restaurants and bars on exposure to second-hand smoke. Prev Med. 2015; (76). doi: 10.1016/j.ypmed.2015.04.012.

40. Majeed BA, Dube SR, Sterling K, Whitney C, Eriksen MP: Opinions about electronic cigarette use in smoke-free areas among U.S. Adults, 2012. Nicotine Tob Res .2015; (17):6. doi: $10.1093 / \mathrm{ntr} / \mathrm{ntu} 235$

41. Amato MS, Boyle RG, Levy D. How to define e-cigarette prevalence? Finding clues in the use frequency distribution. Tob Control. 2016, (25):e1. doi: 10.1136/tobaccocontrol-2015-052236
ACKNOWLEDGEMENTS We would like to thank Jennifer Markol Hall, CAPT Brenda Hamilton, DMD and Mr. Almer Mendoza for the many ways that they helped in accomplishing this study.

CONFLICT OF INTERESTS The authors have completed and submitted the ICME Form for Disclosure of Potential Conflicts of Interest and none reported.

\section{FUNDING}

There was no source of funding for this research.

\section{PROVENANCE AND PEER} REVIEW

Not commissioned; externally peer reviewed 